\title{
Implementing immediate postpartum contraception: a comparative case study at 11 hospitals
}

Michelle H. Moniz ${ }^{1,2^{*}}$ D, Kirsten Bonawitz ${ }^{1}$, Marisa K. Wetmore ${ }^{1}$, Vanessa K. Dalton ${ }^{1,2}$, Laura J. Damschroder ${ }^{3}$, Jane H. Forman ${ }^{3}$, Alex F. Peahl ${ }^{1}$ and Michele Heisler ${ }^{2,4}$

\begin{abstract}
Background: Immediate postpartum long-acting reversible contraception (LARC) is an evidence-based practice, but hospitals face significant barriers to its adoption. Our objective was to examine how organizational context (e.g., size, employee attitudes toward the clinical practice) and implementation strategies (i.e., the actions taken to routinize a clinical practice) drive successful implementation of immediate postpartum LARC services, with a goal of informing the design of future implementation interventions.

Methods: We conducted a comparative case study of the implementation of inpatient postpartum contraceptive care at 11 US maternity hospitals. In 2017-2018, we conducted site visits that included semi-structured key informant interviews informed by the Consolidated Framework for Implementation Research. Qualitative measures of implementation success included stakeholder satisfaction, routinization, and sustainability of immediate postpartum LARC services. Qualitative content analysis and cross-case synthesis explored relationships among organizational context, implementation strategies, and implementation success.

Results: We completed semi-structured interviews with 78 clinicians, nurses, residents, pharmacy and revenue cycle staff, and hospital administrators. Successful implementation required three essential conditions: effective implementation champions, an enabling financial environment, and hospital administrator engagement. Six other contextual conditions were influential: trust and effective communication, alignment with stakeholders' professional values, perception of meeting patients' needs, robust learning climate, compatibility with workflow, and positive attitudes and adequate knowledge about the clinical practice. On average, sites used 18 (range 11-22) strategies. Strategies to optimize the financial environment and train clinicians and staff were commonly used. Strategies to plan and evaluate implementation and to engage patients emerged as promising to address barriers to practice change, yet were often underused.

(Continued on next page)
\end{abstract}

\footnotetext{
* Correspondence: mmoniz@med.umich.edu

'Department of Obstetrics and Gynecology, University of Michigan, $1500 \mathrm{E}$. Medical Center Dr., Ann Arbor, MI 48109, USA

${ }^{2}$ Institute for Healthcare Policy and Innovation, University of Michigan, 2800

Plymouth Rd., Ann Arbor, Ml 48109, USA

Full list of author information is available at the end of the article
}

(c) The Author(s). 2021 Open Access This article is licensed under a Creative Commons Attribution 4.0 International License, which permits use, sharing, adaptation, distribution and reproduction in any medium or format, as long as you give appropriate credit to the original author(s) and the source, provide a link to the Creative Commons licence, and indicate if changes were made. The images or other third party material in this article are included in the article's Creative Commons licence, unless indicated otherwise in a credit line to the material. If material is not included in the article's Creative Commons licence and your intended use is not permitted by statutory regulation or exceeds the permitted use, you will need to obtain permission directly from the copyright holder. To view a copy of this licence, visit http://creativecommons.org/licenses/by/4.0/. The Creative Commons Public Domain Dedication waiver (http://creativecommons.org/publicdomain/zero/1.0/) applies to the data made available in this article, unless otherwise stated in a credit line to the data. 
(Continued from previous page)

Conclusions: Implementation efforts in maternity settings may be more successful if they select strategies to optimize local conditions for success. Our findings elucidate key contextual conditions to target and provide a menu of promising implementation strategies for incorporating recommended contraceptive services into routine maternity practice. Additional prospective research should evaluate whether these strategies effectively optimize local conditions for successful implementation in a variety of settings.

Keywords: Implementation, Contraception, Long-acting reversible contraception, Maternity, Perinatal, Postpartum, Qualitative

\section{Contributions to the literature}

- The literature on implementation efforts in maternity settings is quite sparse.

- Our work newly evaluates how organizational context and implementation strategies affect efforts to implement evidence-based contraceptive services in maternity settings.

- Our findings advance the literature by identifying key contextual conditions to target and providing a menu of promising strategies to include in multicomponent interventions to implement recommended contraceptive services in maternity settings.

- Moreover, our findings advance the science more broadly by beginning to illuminate mechanisms for successful clinical practice change in maternity settings, suggesting that implementation efforts should consider local context and select strategies to optimize conditions for success.

\section{Background}

Immediate postpartum long-acting reversible contraception (LARC) - the insertion of an intrauterine device or contraceptive implant during the delivery hospitalization-is one safe and effective evidence-based intervention for family planning after childbirth [1-4]. Many women express interest in and utilize inpatient LARC services when they are available [5-7]. However, although national guidelines recommend universal access to this service, it is provided almost exclusively at a small number of "early adopter" academic medical centers $[8,9]$. Utilization rates in national samples across the USA remain low $(<1 \%)[9,10]$. Provision of immediate postpartum LARC is now reported in the Centers for Medicare and Medicaid Services' Core Measure set [11], and many states and perinatal quality collaboratives are working to improve access to immediate postpartum LARC for interested individuals [12-18].

Hospitals, however, face significant barriers to offering inpatient LARC services. Non-reimbursement has historically impeded service provision. As insurance payment has become increasingly common, more hospitals have tried to launch these services, but with mixed success $[8,13,14,17,18]$. It is unclear why some hospitals succeed, while others do not. Prior work on clinical practice change suggests that both organizational context and implementation strategies are important [19, 20]. Organizational context refers to all the characteristics of an organization that are not part of the clinical practice itself, such as size, interconnectedness of employees, and employee attitudes toward the clinical practice. Implementation strategies refer to the actions taken to optimize context for change and routinize a new clinical practice. Better understanding context and strategies relevant for implementing evidence-based interventions for peripartum contraceptive services could help improve provision of this care and more broadly inform the design of maternity practice change interventions.

As a case example for better understanding implementation processes in maternity settings and to help inform the design of future implementation interventions, we examined how context and strategies drove successful implementation of immediate postpartum LARC services in early adopter hospitals.

\section{Methods}

We conducted a comparative, multiple case study in early adopter hospitals in the USA. We employed this design with a goal of analyzing similarities and differences across cases in order to produce generalizable knowledge about how and under what circumstances implementation unfolds successfully [21, 22]. We report our methods according to the Consolidated Criteria for Reporting Qualitative Research (COREQ) [23]. We selected COREQ because of its detailed focus on the collection, analysis, and reporting of interview data, such as that used in the current study. The completed checklist is available in Additional file 1.

Because LARC service provision at the hospital level is difficult to identify within national administrative datasets, we conducted a systematic literature search in PubMed to find published literature related to research studies on immediate postpartum contraceptive care. Seventeen unique academic medical centers were identified. Study authors were contacted by email to assess site 
eligibility; six sites were excluded (two did not respond, and four only offered immediate postpartum LARC in the context of a research study). For each hospital, we first identified the "champion" (i.e., the individual leading implementation efforts) and invited them by email to participate in an initial telephone interview for a research project studying implementation of evidencebased peripartum contraceptive care [24-26]. We asked about their experiences with implementation, including potential organization and patient population characteristics that might have impeded or promoted implementation. Two sites declined further participation. Snowball sampling with the remaining nine sites recruited two additional hospitals that had recently implemented services and had not previously conducted research trials of peripartum contraceptive care.

Between August 2017 and September 2018, we conducted single-day site visits, which included semistructured interviews with key informants (i.e., individuals identified by the champion as having unique knowledge about implementation based on their role within the organization), with a goal of representing various stakeholder groups' perspectives in describing implementation (e.g., clinicians, pharmacists, revenue cycle staff, hospital administrators) [24, 25, 27]. Interviews were conducted by MHM and MKW and were audiorecorded with permission and professionally transcribed verbatim. Rarely, due to key informants' availability, interviews were completed by telephone $(n=4)$ or email $(n=1)$. Field notes were taken during interviews and used to develop memos reviewed during analysis.

\section{Theoretical framework}

The Consolidated Framework for Implementation Research (CFIR) guided this research a priori, informing data collection (i.e., semi-structured interview guide) and analyses (i.e., coding framework). CFIR includes 39 contextual conditions that may influence implementation of an evidence-based practice [28]. Our interview guide and analysis were also informed by the Expert Recommendations for Implementing Change (ERIC)-an evidence-based list of 73 discrete strategies that can be bundled in a multicomponent intervention for implementation-which was used to characterize the actions taken at each site to optimize conditions for implementation and routinize inpatient LARC services [20]. The interview guide contained items and probes about each CFIR construct. We also included probes about specific ERIC strategies. Specific items and probes in the interview guide were refined via pilot testing with our institution's interdisciplinary Program on Women's Healthcare Effectiveness Research (PWHER). PWHER members include academic women's health clinicians and health services researchers, many with specific expertise in contraceptive care delivery. Group members provided feedback about CFIR constructs and strategies thought to be less likely relevant to postpartum contraceptive care, guiding the authors' development of a more parsimonious interview guide. The codebook retained all CFIR constructs and ERIC strategies, to allow all potentially relevant themes and relationships to emerge from the data during analysis.

Of note, "champions" appear as a condition in CFIR ("formal implementation leader") and a strategy in ERIC ("identify and prepare champions"); moreover, as implementation leaders, champions are often the source of other ERIC strategies. Because of their central role in implementation, we focus on champions as a condition, but also describe the implementation strategies they executed.

\section{Analysis}

Consensus coding was used throughout, with MHM, $\mathrm{KB}$, and MKW leading the coding process using Dedoose software. In order to understand the relationship between organizational context, strategies, and implementation outcomes, we first devised a three-part qualitative definition of implementation success, based on (1) stakeholder satisfaction, (2) routinization, and (3) sustainability (Fig. 1) [29]. These three outcomes were selected based on their amenability to qualitative measurement and observed variation across sites; other outcomes more suitable to quantitative measurement (e.g., implementation costs, adoption, fidelity) or without variation across sites (e.g., feasibility was universally low) were not included. We assigned ratings of low, medium, or high for each component of implementation success at each site. Second, we conducted a qualitative content analysis, using CFIR constructs as a priori codes, to understand the local conditions for implementation. For each site, coded data were then assigned quantitative ratings indicating valence and strength of influence $(-2$ [strong barrier] to +2 [strong facilitator]) of each CFIR condition on implementation success, as previously described [30] and using the criteria in Table A.1. We summed these ratings in a contextual summary score to understand the relative prevalence of positive and negative influences at each site. Third, we identified implementation strategies used by each site, using the ERIC strategies as an initial checklist and allowing additional strategies to emerge from the data. Finally, we developed matrices with CFIR conditions and associated strategies as rows and hospital cases in columns to support crosscase synthesis investigating (1) conditions most strongly associated with implementation success, including conditions that are essential (e.g., necessary) versus highly influential (e.g., catalyzing or inhibiting) for implementation success and (2) promising strategies to promote 

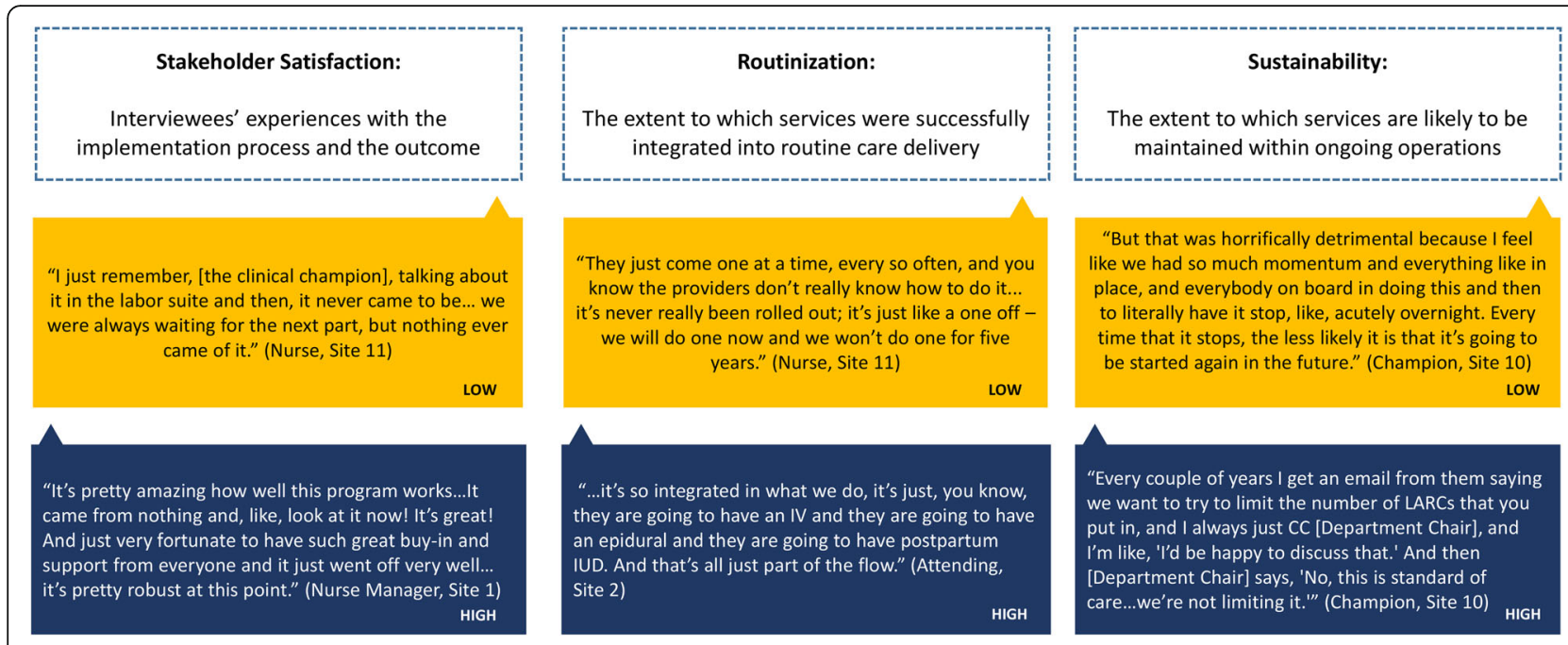

Fig. 1 Qualitative definitions of implementation success

implementation success, based on those effectively used by sites or emerging as underused (i.e., potentially helpful to mitigate unaddressed barriers).

Findings were member-checked with site implementation leaders by phone. Our research team was all female, including research assistants (KB, MKW) and physicians with training in qualitative research (MHM, VKD, MH, AFP) and obstetrics and gynecology (MHM, VKD, AFP). Consultation on qualitative research was provided by researchers with extensive experience in the field and deep familiarity with the implementation literature (LJD, JHF).

\section{Results}

We interviewed 78 key informants (average key informants per site, 7.1 [range 5-10]; mean interview duration, 35 min [range 11-65]) in 11 maternity hospitals (Table 1). Nine sites participated in member-checking phone calls.

Implementation success varied across sites, with site 11 notably unsuccessful across all domains and site 10 implementing services, but with low sustainability prompting de-implementation (Table 2). We identified nine contextual factors as essential or highly influential conditions for successful implementation. The contextual summary scores suggested that some sites enjoyed a highly enabling context for implementation, while others faced more mixed or unfavorable conditions. On average, sites used 18 (range 11-22) implementation strategies (Table 3).

Implementation success was driven by complex interactions between context and implementation strategies. We use qualitative data to illustrate how each condition influenced implementation and describe promising strategies for optimizing each condition for implementation success (Fig. 2).

\section{Essential conditions for success Effective implementation champions}

Condition Implementation champions (i.e., the clinician(s) leading implementation and the team they built) were crucial for success. All clinical champions were obstetrician-gynecologists ( $n=5$ generalist, $n=6$ family planning, $n=1$ maternal-fetal medicine). Effective clinical champions were described as trusted by colleagues, demonstrating grit and resilience, and using a participatory leadership style. Site 11's failure to launch services was partly related to an ineffective clinical champion, who described competing demands on her time and feeling overwhelmed by challenges encountered. Clinical

Table 1 Interviewee characteristics

\begin{tabular}{ll}
\hline Interviewees $^{2}$ & $\mathbf{N = 7 8}$ \\
\hline Frontline clinicians $^{\text {Implementation leaders }}{ }^{\mathrm{a}}$ & 45 \\
Other attending physicians & 12 \\
Residents & 12 \\
Nurses & 9 \\
Midwives & 9 \\
Operations Staff & 3 \\
Pharmacy staff & 24 \\
Administration & 10 \\
Revenue cycle staff & 4 \\
Project managers & 7 \\
Hospital Leadership & 3 \\
\hline
\end{tabular}

${ }^{\mathrm{a}}$ All attending physicians 
Table 2 Relationship between site context, qualitative themes, and implementation success

\begin{tabular}{|c|c|c|c|c|c|c|c|c|c|c|c|}
\hline Characteristic & Site 1 & Site 2 & Site 3 & Site 4 & Site 5 & Site $6^{a}$ & Site 7 & Site 8 & Site 9 & Site 10 & Site $11^{\mathrm{a}}$ \\
\hline \multicolumn{12}{|l|}{ Organizational characteristics } \\
\hline Annual delivery volume & 5500 & 3000 & 2400 & 3500 & 3000 & 5500 & 3000 & 2500 & 4500 & 4000 & 8500 \\
\hline Number of attendings on labor and delivery & 36 & 30 & 15 & 33 & 45 & $N A^{b}$ & 77 & 20 & 51 & 50 & 50 \\
\hline \multicolumn{12}{|l|}{ Qualitative measures of implementation success } \\
\hline Stakeholder satisfaction & High & High & High & High & Med & Med & Med & Med & Med & High & Low \\
\hline Routinization & High & High & High & High & High & High & High & High & High & High & Low \\
\hline Sustainability & High & High & Med & Med & Med & Med & Med & High & High & Low & $N A^{b}$ \\
\hline \multicolumn{12}{|l|}{ Organizational context for implementation ${ }^{c}$} \\
\hline \multicolumn{12}{|l|}{ Essential conditions } \\
\hline Implementation champion(s) & $2^{+}$ & $2^{+}$ & $2^{+}$ & $2^{+}$ & $2^{+}$ & $2^{+}$ & $2^{+}$ & $1^{+}$ & $1^{+}$ & $2^{+}$ & $2^{-}$ \\
\hline Financial environment & $2^{+}$ & $2^{-}$ & $1^{+}$ & $2^{-}$ & $2^{-}$ & $1^{-}$ & $2^{-}$ & $2^{-}$ & 0 & $2^{-}$ & $2^{+}$ \\
\hline Hospital administrators' engagement & $2^{+}$ & $2^{+}$ & $1^{+}$ & $2^{+}$ & $1^{+}$ & $1^{+}$ & $1^{x}$ & $2^{+}$ & $1^{+}$ & $1^{+}$ & $2^{-}$ \\
\hline \multicolumn{12}{|l|}{ Highly influential conditions } \\
\hline Networks and communications & $2^{+}$ & $2^{+}$ & $2^{+}$ & $1^{x}$ & 0 & $2^{x}$ & $1^{+}$ & $1^{+}$ & 0 & $1^{x}$ & $1^{x}$ \\
\hline Compatibility with norms and values & $2^{+}$ & $2^{+}$ & $2^{+}$ & $1^{+}$ & $2^{+}$ & $2^{+}$ & $1^{+}$ & $2^{+}$ & $1^{+}$ & $2^{+}$ & $1^{+}$ \\
\hline Patient needs and resources & $2^{+}$ & $2^{+}$ & $2^{+}$ & $1^{+}$ & $2^{+}$ & $2^{+}$ & $1^{+}$ & $2^{+}$ & $1^{+}$ & $2^{+}$ & $2^{x}$ \\
\hline Learning climate & $2^{+}$ & $1^{+}$ & $2^{+}$ & $2^{+}$ & $2^{+}$ & $2^{+}$ & $1^{+}$ & $1^{x}$ & 0 & $2^{+}$ & $2^{x}$ \\
\hline Compatibility with workflow & $1^{x}$ & $1^{-}$ & $1^{+}$ & 0 & $1^{-}$ & $1^{-}$ & $1^{+}$ & $1^{-}$ & $1^{-}$ & 0 & $2^{x}$ \\
\hline Clinician/staff attitudes, beliefs, \& knowledge & $2^{+}$ & $2^{+}$ & $2^{+}$ & $2^{+}$ & $1^{+}$ & $1^{+}$ & $2^{x}$ & $2^{x}$ & $2^{x}$ & $1^{+}$ & $1^{-}$ \\
\hline Contextual summary score ${ }^{d}$ & 34 & 32 & 34 & 27 & 16 & 19 & 10 & 1 & 2 & 17 & -18 \\
\hline \multicolumn{12}{|l|}{ Overview of implementation process } \\
\hline Number of implementation strategies used & 20 & 16 & 22 & 19 & 17 & 16 & 20 & 22 & 11 & 16 & 13 \\
\hline Duration of implementation (months) & 16 & 36 & 4 & 7 & 48 & 18 & 60 & 10 & 12 & 27 & $N A^{e}$ \\
\hline
\end{tabular}

${ }^{\mathrm{a}}$ Member-checking was not completed for these sites

bData unavailable

${ }^{c}$ Organizational context ratings reflect influence of the contextual factor on implementation at each site, $2^{+}$denotes a strong positive influence, $1^{+}$denotes a weak positive influence, $1^{-}$denotes a weak negative influence, $2^{-}$denotes a strong negative influence, $2^{\mathrm{x}}$ denotes a strong mixed influence, $1^{\mathrm{x}}$ denotes a weak mixed influence, 0 denotes no apparent influence

${ }^{\mathrm{d}}$ Summary score reflects the sum of ratings for all 39 CFIR constructs (Score $=$ [positive] - [negative + mixed])

e Implementation was ongoing at time of interview

champions often required support from an interprofessional team, whose members addressed barriers in organizational silos outside the clinical champion's reach. For example, one site's pharmacy manager described how he dissipated resistance from colleagues before the clinical champion ever formally introduced the initiative. Clinical champions and teams effected change at many levels-advocating for more favorable payer reimbursement policies, engaging hospital administrators, driving operations and infrastructure changes, and building support for change among their colleagues.

Strategies Though all sites had an identified clinical champion, none had any training or tools to prepare them for their highly influential role in implementation. Nearly all cited need for more support (e.g., protected time, administrative support). Two sites used project managers, who reduced burden on the clinical champion and offered a unique skillset for facilitating teamwork and problem-solving. Clinical champions and teams often cited the utility of scale-up approaches (e.g., initially launching one LARC device type, piloting services with a small group of providers). Few champions/teams utilized implementation planning strategies, and many experienced ensuing inefficiencies, need for adaptations, and stakeholder frustration. No implementation teams robustly evaluated implementation outcomes (e.g., by monitoring implementation costs, stakeholder satisfaction, adoption of new workflows, patient utilization of immediate postpartum LARC, or the patient experience of postpartum contraceptive care).

\section{An enabling financial environment}

Condition Payer reimbursement policies profoundly affected implementation success. All hospitals faced risk of financial losses associated with providing inpatient LARC services due to non-universal reimbursement by 
Table 3 Implementation strategies for immediate postpartum contraceptive services and frequency of utilization by study sites

\begin{abstract}
Strategies $^{\text {a }}$
Strategies to plan and lead implementation

Identify and prepare champion(s): identify and prepare individuals who dedicate themselves to supporting a new practice and overcoming indifference or resistance

Build an implementation coalition: recruit and cultivate relationships with partners in the implementation effort

Promote network weaving: cultivate high-quality working relationships within and across organizational units to promote information sharing, collaborative problem-solving, and a shared vision related to implementing the innovation
\end{abstract}

\section{Sites utilizing strategy}

\begin{tabular}{llllllllllll}
\hline Total & 1 & 2 & 3 & 4 & 5 & 6 & 7 & 8 & 9 & 10 & 11
\end{tabular}

Conduct local consensus discussions: include stakeholders in discussions about whether the clinical innovation appropriately addresses an important problem

Conduct local needs assessment: collect and analyze data (e.g., baseline contraceptive counseling and use rates) related to the need for the innovation

Assess for readiness; identify barriers and facilitators: assess various aspects of an organization to determine its readiness to implement, barriers that may impede implementation, and strengths that can be used in the implementation effort

Tailor strategies: tailor the implementation strategies to address barriers and leverage facilitators that were identified through earlier data collection

Develop a formal or informal implementation blueprint: Develop a description of the (1) aim/purpose of the implementation, (2) scope of the change (e.g., units affected),

(3) timeframe and milestones, and (4) appropriate performance measures

Obtain stakeholder feedback about the implementation plan: formally and informally soliciting front-line workers' opinions to refine the implementation plan

Facilitation: a process of interactive problem-solving and support in the context of a recognized need for improvement and a supportive interpersonal relationship

Assess and redefine workflow: map current work processes and plan for desired work processes, identifying changes necessary to routinize the clinical innovation

Stage implementation scale up: phase implementation efforts by starting with small pilots or demonstration projects and gradually move to a system-wide rollout

Strategies to optimize financial environment

Access new funding: access money to facilitate implementation

Place innovation on FFS lists/inpatient formulary: work to place the clinical innovation on lists of actions for which providers can be reimbursed (e.g., a drug is placed on a formulary, a procedure is now reimbursable)

Strategies to optimize for infrastructure change

Change record systems: change electronic medical records to allow better patient care or assessment of clinical outcomes

Change physical structure and equipment: adapt the physical structure/equipment to accommodate the intervention (e.g., adding a Pyxis ${ }^{\top \mathrm{M}}$ or device insertion supplies)

Strategies to train, educate, and support clinicians and staff

Provide dynamic training and educational activities: use interactive methods to teach stakeholders (e.g., providers, operations staff) about the innovation

Develop and distribute educational materials: disseminate manuals and toolkits

Conduct ongoing training: offer follow-up training, advanced training, booster training, purposefully spaced training, training to competence, structured supervision

Remind clinicians: develop reminder systems designed to help clinicians to recall information and/or prompt them to use the clinical innovation

Provide clinical supervision: expert clinician offers ongoing supervision

Organize clinician and staff team meetings: support the teams implementing the innovation and protect time to reflect on their efforts and share lessons learned

Engage local opinion leaders: activate individuals identified by colleagues as "influential" to motivate colleagues to adopt the clinical innovation; dampen resistance among opinion leaders, if needed

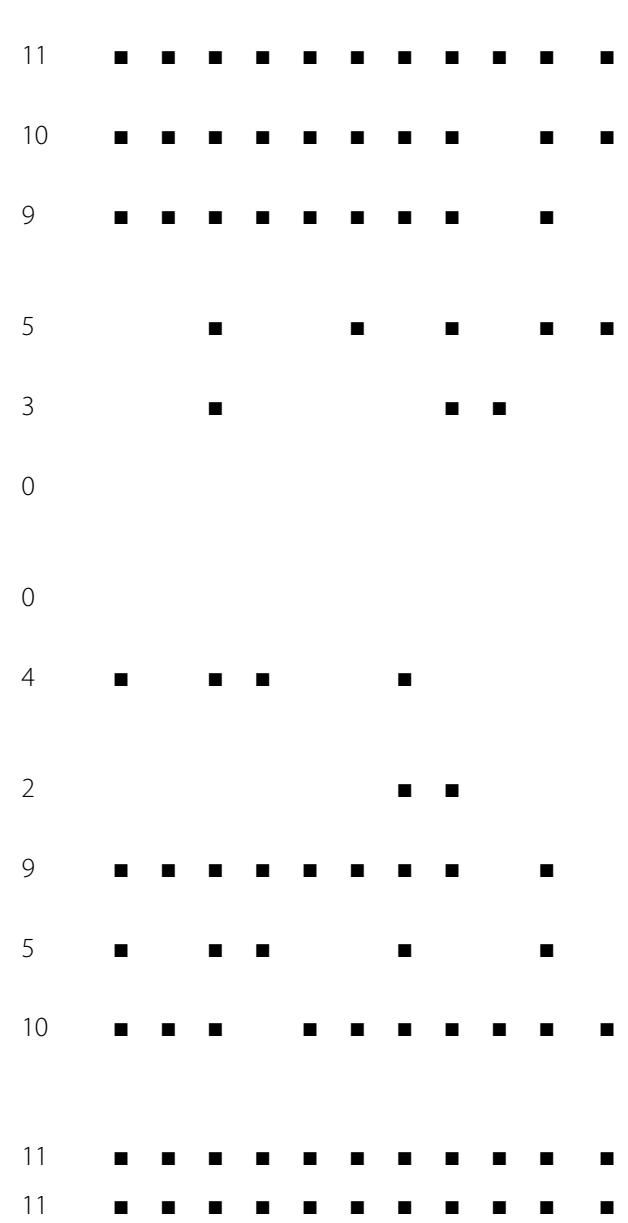

10

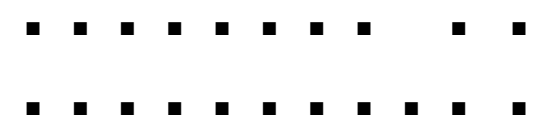

11

10

10

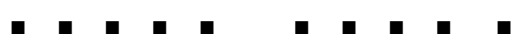

10

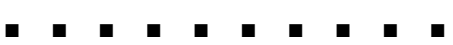

4

5

0 
Table 3 Implementation strategies for immediate postpartum contraceptive services and frequency of utilization by study sites (Continued)

\begin{tabular}{|c|c|c|c|c|c|c|c|c|c|c|c|c|}
\hline \multirow[t]{2}{*}{ Strategies $^{\mathrm{a}}$} & \multicolumn{12}{|c|}{ Sites utilizing strategy } \\
\hline & Total & 1 & 2 & 3 & 4 & 5 & 6 & 7 & 8 & 9 & 10 & 11 \\
\hline \multicolumn{13}{|l|}{ Strategies to engage patients } \\
\hline $\begin{array}{l}\text { Prepare patients to be active participants: prepare patients to inquire about care guidelines } \\
\text { and available treatment options and request the clinical innovation from their providers } \\
\text { desired }\end{array}$ & 6 & - & & & & - & & - & - & - & & - \\
\hline Involve patients in implementation planning: solicit and use patient feedback & 0 & & & & & & & & & & & \\
\hline $\begin{array}{l}\text { Engage community resources: utilize health departments, non-profits, resources for addressing } \\
\text { social determinants of health, and reproductive justice experts }\end{array}$ & 1 & & - & & & & & & & & & \\
\hline \multicolumn{13}{|l|}{ Strategies to evaluate Implementation } \\
\hline Plan for outcome evaluation: identify relevant outcomes, measures, and data sources & 2 & & & - & & & & - & & & & \\
\hline $\begin{array}{l}\text { Develop processes and tools for quality monitoring: develop, test, and utilize systems and } \\
\text { procedures to monitor clinical processes or outcomes related to the innovation }\end{array}$ & 5 & & & - & - & - & & & - & & - & \\
\hline $\begin{array}{l}\text { Evaluate the implementation: monitor progress and adjust clinical practices and } \\
\text { implementation strategies to continuously improve the quality of care }\end{array}$ & 8 & - & - & - & - & - & - & - & - & & & \\
\hline $\begin{array}{l}\text { Audit and feedback: collect clinical performance data and give it to clinicians and } \\
\text { administrators to monitor, evaluate, and modify provider behavior }\end{array}$ & 0 & & & & & & & & & & & \\
\hline
\end{tabular}

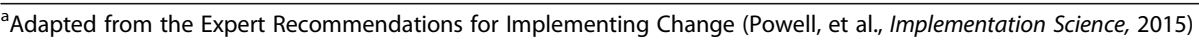

NOTE: Strategies used by sites but not clearly linked to implementation outcomes include: conduct cyclical small tests of change ( $n=1)$, use advisory boards and work groups $(n=2)$, use train the trainer strategies $(n=1)$, and revise professional roles $(n=1)$

$L A R C$ Long-acting reversible contraception

payers. Evidence of financial losses often led to interruptions in service provision and, at site 10 , program deimplementation.

Strategies Many sites described advocating for public and private payer reimbursement for inpatient LARC care. Some hospitals used private donor-sponsored LARC devices to minimize financial losses and thereby expand access to services, but grants were time-limited, and patient demand could outpace supply. Some implementation teams successfully used consensus discussions to increase hospital administrators' willingness to absorb financial losses.

\section{Hospital administrator engagement}

Condition Opposition from hospital administrators nearly guaranteed implementation failure. Site 11 interviewees described how implementation was encumbered by department leaders' disagreement with the clinical champion about processes for training providers and consenting patients for inpatient intrauterine devices (IUDs), and ultimately, lack of permission to proceed with implementation. Some other sites' leaders were "philosophically onboard," but grappled with the potential financial implications of offering services. If supportive, hospital administrators could promote sustainability of service provision.
Strategies Local consensus discussions were important to overcome opposition and secure buy-in from administrators.

\section{Highly influential conditions for success Trust and effective communication}

Condition Many sites lacked pre-existing relationships and communication processes across clinicians and operations staff and struggled to build trust among individuals with divergent expertise, priorities, and reporting structures. Mistrust and ineffective communication undermined the collaboration necessary to address implementation challenges and ensure efficient frontlines care delivery.

Strategies Network weaving (i.e., intentional efforts to cultivate high-quality working relationships) and creating infrastructure for shared problem-solving and accountability (e.g., recurring team meetings with a shared implementation task list) were helpful strategies to support the implementation team. Many champions used standing meetings among divisions and unit committees to facilitate dialogue and strengthen relationships across otherwise siloed frontlines clinicians and staff.

\section{Alignment with stakeholders' professional values}

Condition Successful implementation relied on stakeholders believing the new practice aligned with their 


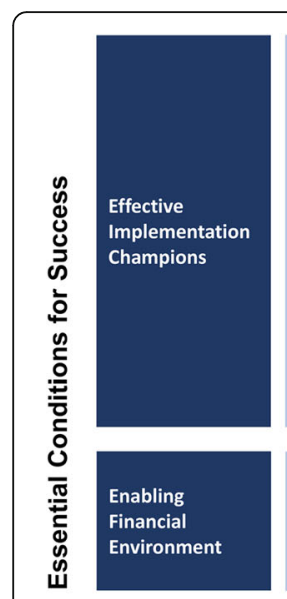

“...[Clinical Champion] had to fight a lot of battles... at every level in terms of the level of billing, the level of pharmacy, you know, all of the details you don't really think about... she really had to iron out... she just wanted to get it done." (Resident, Site 7)

"I really was the person doing all of this... I certainly had help from other people but in terms of the actual work of implementing this, it was really me and, honestly, that's a huge part of also why the IUDs, I think, haven't happened yet, because I lost my protected time... [and] I also became the medical director of the outpatient clinic which kind of sucked a lot of my time up and... it just kind of never happened... I think that if I had had more time, I may have been able to do it." (Champion, Site 11)

"So, even before the engagement of [Implementation Champion] to come to the subcommittee meeting, I had already - we had already had multiple meetings where I said, no, this is a project that makes sense for pharmacy... we had that resolved behind the scenes, before going to the subcommittee, the P\&T subcommittee, and the requirement for that subcommittee was for the physician champion to come and make a case for them... they show up and a lot of the pharmacists had already brought literature to support and why this product [Liletta] was better than the one they currently have on the formulary... So, we basically had to present the case and the pharmacy did a lot of work before we ever showed up for the meeting." (Pharmacy Manager, Site 3)

\section{"[Implementation was not even considered until [Medicaid] reimbursement was guaranteed." (Champion, Site 4)}

"I think it may be a $\$ 250-\$ 300,000$ hit I would take on the inpatient setting which I would not get reimbursed for. But, really, we asked the question of our CEO, this is really for the greater good, and we want to take that hit. And they said, yes, we are. And it was back on me and my team to- [sic] our cost initiatives elsewhere... but this is the right thing for us to do." (Pharmacist, Site 2)

\section{Hospital} Administrato Engagement

"I wanted to make sure that we would be allowed to consent patients in labor. [the Chief Medical Officer] said at that time, like, 'well, I think that we will have to talk to legal about that'... no consensus was ever reached on that... he brought up the concern that maybe we should actually have a separate privilege for this... I know he was definitely just trying to be safe, but that definitely kind of put a wrench in the works" (Champion, Site 11)

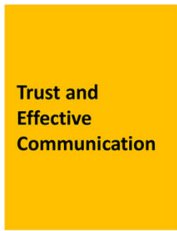

Alignment with Stakeholders'

Professional Values

"There is probably a gap between us and billers... it's a hard relationship to form... These aren't people that I see every day. I honestly couldn't tell you the last time I had with billing offices... it's been really easy for us to work as a department of clinicians, but going to those, like, non-clinical relationships has been really hard." (Champion, Site 10)

"So billing was very siloed and pharmacy was pretty siloed and even the providers didn't understand the billing side and the technicalities of it. But in order to get buy in really quickly at the beginning, I started to essentially try to create relationships among team members... In essence, it just took the listening. You know, I would hear something, and say, what I think I hear you saying .... and then, almost like, publicly recognizing that it was a good suggestion, started to get more buy in... I think some of the just kind of team camaraderie and just saying it out loud... it kind of got us together" (Project Manager, Site 7)

"...everybody was open to the idea and everybody had the end goal that this was going to be beneficial for the patient whether, yeah, it was kind of cumbersome getting information but who does it benefit? We work for them. We work for the patient... and so, when you present it to them like that, how could you as a nurse or physician, you say no to that?" (Nursing, Site 3)

“I know it's difficult because doctors are very like medical-minded, like 'We just want to treat the patient, we don't want to worry about that other stuff,' ... the financial piece is an important part of care as well...." (Revenue Cycle Specialist, Site 8)

"And I think that there is just a general sense that the six-week postpartum visit is kind of an antiquated time to provide postpartum contraception... providers were kind of responding to patient needs, as well as kind of getting the most up to date research coming out and saying this is safe and effective and acceptable... We want to make this available to our patients. And think since, like over time, now patients are requesting this as an option." (Attending physician, Site 2)

Perception of Meeting Patients' Needs "...we lean towards recommending long-acting methods... this is probably our area of greatest need right now, is to make sure that we are providing just the best counseling that we can that is neither biased or coercive... so we are working with ACOG LARC program to bring in an outside speaker to do grand rounds on contraceptive counseling to address bias and coercion and...just talk about evidence-based methods of counseling" (Attending physician, Site 6)

\section{Robust Learning} Climate

\section{"...nursing was able to feel their identity and their importance and as being as important to the initiative as the provider team. And I think that really made a difference because nursing feels like they own this project in conjunction with provider" (Nurse Manager, Site 1)}

"My goal was just to change the work flow as little as possible, and make it as easy as possible to do this." (Champion, Site 4)

"We had to get the key players so, sometimes, there would be more people added to each meeting... let's add the techs, pharmacy techs because they are the ones who are going to drop it off and they have to make sure they put it in the correct spot... you have to talk to the person on the front line, [who is] inserting, who is going to be taking count of the Nexplanons, and who is going to get stuff ready... and we kind of all collaborated together to figure out a process of who was going to be responsible for what and how we are going to get this to the patient." (Nurse, Site 3 )

\section{"...we still have one group [of attendings] here... who are still very resistant to do this, and they insist that all their patients} come back for follow up." (Champion, Site 9 )

Positive

Attitudes and

Adequate

Knowledge

About the

Clinical Practice

"Like, you need to be able to tell them which form to use, which lines need to be filled out, and where it needs to be sent because that's a total roadblock, and the clinicians don't speak that, so you have to have somebody that can really clearly describe that for them." (Champion, Site 6)

"the other thing I think is really important is reviewing at least once a year on technique. And I knew we didn't do a good enough job training because people would ask me questions that were clearly covered, like, for example, use of antiseptic, you know, ring or no ring on the cervix. The whole thing about people using the actual inserter and we never talked about that. I think people - and once we sort of found out that, oh, yeah, they are not what we thought was happening is not happening, we changed and, you know, re-did the training" (Champion, Site 2)
Promising strategies: Identify and prepare champions; Build a coalition: Conduct local needs assessment; Assess for readiness and identify barriers and facilitators; Tailor strategies; Develop a blueprint; Obtain feedback about the implementation plan; Stage scale up; Facilitation; Plan for outcome evaluation; Develop processes for quality monitoring; Evaluate implementation (counseling rates, method utilization rates, patient-reported outcomes about patient-repor
services)

\section{Promising strategies:} Conduct local consensus discussions; Access new funding; Place innovation on inpatient formulary

Promising strategies: Conduct local consensus discussions

Promising strategies: Promote network weaving; Organize clinician and staff team meetings

Promising strategies: Conduct local consensus discussions; Project financial implications

\section{Promising strategies:}

Involve patients in

implementation planning;

Prepare patients to be active

participants; Engage community resources

Promising Strategies: Facilitation; Obtain stakeholder feedback

\section{Promising strategies:}

Assess \& redesign workflow;

Obtain stakeholder feedback;

Change record systems to

streamline documentatio

Change physical structure;

Change physical structure and equipment; Remind
Make billing easier

\section{Promising strategies:}

Provide dynamic training and education for clinicians and staff; Develop and distribute educational materials; Conduct ongoing training; Provide clinical supervision; Organize clinician and staff team meetings; Engage local opinion leaders; Audit \& feedback about performance (e.g., counseling rates, contraceptive utilization, patient experience of care)

Fig. 2 Qualitative data illustrating the effects of contextual conditions on implementation 
professional values. Clinicians generally embraced the new practice, driven by perceptions that enhancing contraceptive access was central to their professional mission. Conversely, pharmacists and billing specialists often described inpatient LARC provision as a "moneylosing proposition" at odds with their fiduciary obligations. Clinician frustration that the "device gatekeepers" were not won over by evidence of the initiative meeting patients' needs and operations staff wariness that clinicians would distribute devices without genuine consideration of the hospital's financial sustainability often jeopardized implementation. Site 6 spent 4 years addressing this barrier.

Strategies Occasionally, champions effectively engaged operations staff by using consensus discussions to align the initiative with the hospital's clinical mission. Usually, more pragmatic approaches were needed (e.g., projecting potential financial outcomes, providing proof of payment for a handful of pilot test devices).

\section{Perception of meeting patients' needs}

Condition Many interviewees characterized immediate postpartum LARC services as an important opportunity to address unmet patient needs related to access barriers and individuals' preferences for contraceptive care (e.g., IUD insertion under regional anesthesia). In most sites, perceptions that offering inpatient LARC services better met patients' needs strongly promoted adoption and stakeholder satisfaction. Many interviewees described tensions between enhancing contraceptive access while also promoting patient-centeredness and equity of care.

Strategies No sites involved patients or patient advocacy groups in implementation planning or evaluation. Most sites engaged in some efforts to prepare patients to be active participants in care (e.g., developing educational handouts about contraceptive options).

\section{Robust learning climate}

Condition Robust learning climates, where clinicians and staff described feeling essential and empowered to shape change, catalyzed implementation and stakeholder satisfaction. In strong learning climates, champions could actively partner with colleagues to design new clinical workflows, problem-solve around challenges, and make real-time refinements to care delivery postimplementation.

Strategies Champions promoted a positive learning climate by engaging in facilitation (a process of interactive problem-solving), expressing curiosity about colleagues' needs and involving them in decision-making, creating psychological safety for clinicians trying a new practice (e.g., giving their cellphone number to call whenever needed), and making colleagues' contributions to implementation visible to peers and leaders.

\section{Compatibility with workflow}

Condition Embedding inpatient LARC into daily care delivery routines required steps to minimize workflow disruptions, including establishing communication processes across teams and settings, making devices readily available, optimizing the electronic medical record for documentation and device ordering, and streamlining billing and coding processes. At most sites, workflow changes developed organically, often resulting in inefficiencies, provider confusion and frustration, interruptions to service provision, need for adaptations, and dampening of stakeholder satisfaction.

Strategies At two sites, implementation teams effectively improved workflow compatibility by prospectively involving everyone affected by changes and, at one site, using a workflow process map to delineate roles and responsibilities. Multiple sites changed electronic medical records (e.g., creating a standardized documentation element for contraceptive counseling) and purchased new equipment (e.g., long forceps for IUD insertion).

\section{Positive attitudes and adequate knowledge about the clinical practice}

Condition All sites described how individual clinicians with negative perceptions could insidiously undermine service delivery. Nurses concerned about adverse effects on breastfeeding or providers worried about expulsion rates could preclude some patients from meaningful access, even when inpatient LARC services were "available" at a site. Clinicians and staff also had significant knowledge and skill gaps regarding immediate postpartum LARC.

Strategies Champions and team members were crucial for overcoming resistance and addressing informational needs. Most champions led dynamic trainings, including didactics (e.g., Grand Rounds, training sessions for billing staff) and hands-on simulation training in postplacental IUD insertion. One-time training was often described as insufficient; champions cited need for ongoing training and clinical supervision. Strategies that might have helped address individuals' resistance to change include meetings to reflect on the new practice and share lessons learned, activating local opinion leaders, and providing performance audit and feedback. 


\section{Discussion}

We identify key contextual conditions to target and a menu of promising strategies to inform the design of future multi-component interventions for implementing immediate postpartum LARC care.

Our findings suggest that immediate postpartum LARC implementation should focus first on supporting champions, creating an enabling financial environment, and engaging hospital leaders. Prior work has emphasized the importance of champions for immediate postpartum LARC implementation $[8,13,17,31]$. The current study sheds light on why and how champions are so essential, by newly identifying the myriad strategies champions deploy to promote successful implementation. Our results suggest that many champions need more support, including protected professional effort and administrative support from project managers, as other research notes [32]. Our findings also call for multidisciplinary implementation teams and suggest that efforts may benefit from including trained implementation scientists. A recent integrative review identified only five studies of solo vs. team champions for clinical practice change efforts; all documented that teams benefit from initiatives requiring complex behavior change [3337]. We add rich qualitative evidence that implementation teams are essential for boundary-spanning-helping champions address barriers in organizational silos outside their sphere of influence [38]. Specifically, we found that implementation team members helped champions identify barriers, mitigate emerging challenges, and act as opinion leaders to engage their peers. These findings have important implications for the design, implementation, and evaluation of implementation interventions, suggesting that the work of measuring barriers and facilitators, selecting aligned implementation strategies, deploying strategies, and evaluating and refining implementation efforts may best be achieved by implementation teams that maximally leverage members' professional relationships and knowledge of local culture. An enabling financial environment was also essential to implementation success, as others have noted [17, 39-41]. Efforts to promote universal reimbursement and seamless payment processes for inpatient LARC services would remove a major obstacle to hospital adoption of this care and promote more equitable patient access. Additionally, we newly document how hospitals may engage in creative strategies to mitigate or absorb potential financial losses, even in the current coverage climate.

We identified multiple inefficiencies in implementation, suggesting the need for additional implementation strategies. Sites may have benefited from more intentional efforts to plan implementation, build relationships across organizational silos, dampen resistance from individual clinicians, and evaluate quality of care outcomes (e.g., contraceptive counseling rates, contraceptive utilization, patient experience of care). These findings may seem obvious, but this study suggests that these efforts are not currently being undertaken. Such efforts may have more efficiently and effectively addressed barriers related to networks and communications, compatibility with norms and workflow, and individual clinicians' resistance to change and guided efforts to optimize the efficiency, equity, and patientcenteredness of care delivery processes.

The paucity of efforts to engage patients in implementation surprised us. At all sites, clinicians cited a desire to better meet patient needs as the impetus for launching inpatient LARC services, but did not invite patients to participate in the design or evaluation of new services. Meaningfully engaging patients in redesigning healthcare services is associated with improved outcomes and healthcare quality [42]. Patient engagement may be particularly important for contraceptive services. Historically and in contemporary practice, women of color, immigrants, incarcerated individuals, youth, individuals with disabilities, and lower income people have experienced being directed or coerced into using particular contraceptive methods [43-45]. It is thus crucial that efforts to improve contraceptive care quality include patients and communities in program design and evaluation, with an explicit goal of promoting patientcenteredness and reproductive justice.

At all sites, successful maternity practice change was complex, requiring significant human capital and coordination across diverse stakeholders. Though implementation is often framed as complex across many sectors of healthcare, maternity care may be exceptionally so. Butler et al [46] refer to complexity with respect to intervention, multiple synergies, multiple professions involved, the need for adaptations to ensure strong fit between existing and new processes, and engagement by diverse professions and roles across multiple organizational boundaries. Maternity care is exceptionally complex: inpatient maternity units provide emergency services for pregnant individuals, host operating rooms and sometimes intensive care beds, and deliver routine labor, delivery, and postpartum recovery services for mothers and infants. Volume and acuity of care are often unpredictable. The importance of workflow compatibility is particularly important to the maternity setting and must include multiple services and departments. Our findings, however, highlight a relative lack of pre-existing relationships across the many healthcare workers who contribute to care delivery (e.g., clinicians, billing staff, pharmacy staff). There are increasing calls for more meaningful involvement of patients in process redesign [47-49]. In our study, use of postpartum contraception, the clinical innovation, is largely driven by patient preferences; thus, user-centered design approaches may 
be particularly important for uptake. While it is not necessarily surprising that planning and evaluating implementation efforts are important, we, like others, have found that these activities are inconsistently done. Our findings call for more support for individuals leading change in complex care settings, to enable robust implementation planning and evaluation activities and more active approaches to engaging patients in redesign of maternity services.

A key working assumption within implementation science is the need to tailor implementation strategies to address contextual barriers and leverage facilitators [50, 51]. Researchers have highlighted the importance of understanding contextual influences on implementation and then carefully choosing strategies and designing parameters of those strategies based on knowledge of context [50-52]. Our findings provide a mapping from contextual determinants using a widely cited implementation science framework and mapping actual use of strategies to the ERIC list of strategies, also widely cited. Others have identified combinations of strategies leading to better outcomes $[53,54]$ or using a group process to choose strategies to use in future phases of work [55]. Our study is unique in that first, we describe a process to identify high-priority contextual factors that appear to be associated with desired outcomes; then, based on those determinants, we describe promising strategies used by higher-performing hospitals or that were underused and had potential for addressing each high-priority determinant. Qualitative data provide rich detail about how determinants manifest within the inpatient maternal settings and how strategies relate to those determinants. Strategies paired to determinants largely align with recommendations from the CFIR-ERIC Matching Tool [52]. Thus, our findings provide an initial set of strategies based on implementation experiences across 11 hospitals providing inpatient postpartum LARC services, and at the same time, provide support for earlier work to match ERIC strategies to address contextual barriers. An important step for future work will be to further operationalize $[50,56]$ and prospectively evaluate these strategies in a prospective, multi-site trial conducted in heterogeneous maternity care settings. Such research will further illuminate mechanisms for successful clinical practice change in complex care settings.

Study strengths include rich contextual variation across sites, results achieved in real-world settings, and robust qualitative methodology. Our study design is also subject to limitations. Our sampling strategy identified only academic, early adopter hospitals. Most immediate postpartum LARC is provided at academic centers $[8,9]$, so this was a reasonable sample. Specific contextual factors and strategies identified here may not be generalizable to all settings, but our findings underscoring the importance of intentionally designing implementation interventions to address local context are presumably applicable across settings. Cross-sectional interviews are subject to recall and social desirability bias and may not have captured subtle attitudes or changes in context or outcomes. We did not include patients in this study, due to our focus on implementation and feasibility at the hospital level. This is a notable limitation. Our findings emphasize the critical need to evaluate patients' preferences and experience of care to better guide efforts to improve peripartum contraceptive services.

\section{Conclusions}

Implementation efforts in maternity settings should consider local context and select strategies to optimize conditions for success. Our findings provide a roadmap for this process, elucidating the key contextual conditions to target and providing a menu of promising implementation strategies for embedding recommended peripartum contraceptive care into routine maternity practice.

\section{Abbreviations}

LARC: Long-acting reversible contraception; CFIR: Consolidated Framework for Implementation Research; ERIC: Expert Recommendations for Implementing Change; IUD: Intrauterine device

\section{Supplementary Information}

The online version contains supplementary material available at https://doi. org/10.1186/s43058-021-00136-7.

Additional file 1. COREQ checklist. PDF file COREQ (COnsolidated criteria for REporting Qualitative research) Checklist Items included in report and respective page numbers on which they appear

Additional file 2. Table A.1 Criteria $^{1}$ for assigning quantitative ratings to CFIR constructs.

Acknowledgements

Presented at the AcademyHealth Annual Research Meeting, June 2-4, 2019, Washington, D.C.

Authors' contributions

$M M, K B$, and MW collected and analyzed all data. VD, LD, JF, AP, and MH assisted in interpreting data. MM and $\mathrm{MH}$ drafted the initial manuscript. The authors read and approved the final manuscript.

\section{Funding}

Michelle Moniz is supported by the Agency for Healthcare Research and Quality (AHRQ) grant \#K08 HS025465. Vanessa Dalton is supported by AHRQ grant \#R01 HS023784. Michele Heisler is supported by the National Institutes of Health (NIH) National Institute of Diabetes and Digestive and Kidney Diseases grant \#P30 DK092926. The AHRQ and NIH played no role in the study design; in the collection, analysis, and interpretation of data; in the writing of the report; or in the decision to submit the article for publication.

\section{Availability of data and materials}

The datasets used and/or analyzed during the current study are available from the corresponding author on reasonable request.

\section{Declarations}

Ethics approval and consent to participate

This study was deemed exempt human subjects research by the University of Michigan Institutional Review Board (HUM00127245; approved 4/27/2017). 


\section{Consent for publication}

Not applicable

\section{Competing interests}

The authors declare that they have no competing interests.

\section{Author details}

'Department of Obstetrics and Gynecology, University of Michigan, $1500 \mathrm{E}$. Medical Center Dr., Ann Arbor, MI 48109, USA. ${ }^{2}$ Institute for Healthcare Policy and Innovation, University of Michigan, 2800 Plymouth Rd., Ann Arbor, MI 48109, USA. ${ }^{3}$ Veterans Affairs Center for Clinical Management Research, VA Ann Arbor Healthcare System, 2215 Plymouth Rd., Ann Arbor, Ml 48105, USA. ${ }^{4}$ Department of Internal Medicine, University of Michigan, 1500 E. Medical Center Dr., Ann Arbor, Ml 48109, USA.

\section{Received: 5 January 2021 Accepted: 19 March 2021}

\section{Published online: 12 April 2021}

\section{References}

1. American College of Obstetricians and Gynecologists' Committee on Obstetric Practice. Committee opinion no. 670: immediate postpartum longacting reversible contraception. Obstet Gynecol. 2016;128(2):e32-7. https:// doi.org/10.1097/AOG.0000000000001587.

2. American College of Obstetricians Gynecologists' Committee on Obstetric Practice, Association of Women's Health Obstetric Neonatal Nurses. Committee opinion no. 666: optimizing postpartum care. Obstet Gynecol. 2016;127(6):e187-92. https://doi.org/10.1097/AOG.0000000000001487.

3. American College of Obstetricians and Gynecologists. ACOG practice bulletin no. 121: long-acting reversible contraception: implants and intrauterine devices. Obstet Gynecol. 2011;118(1):184-96. https://doi.org/10.1 097/AOG.0b013e318227f05e.

4. Curtis KM, Tepper NK, Jatlaoui TC, Berry-Bibee E, Horton LG, Zapata LB, et al. U.S. medical eligibility criteria for contraceptive use, 2016. MMWR Recomm Rep: Morb Mortal Weekly Rep Recommend Rep/Centers Dis Contr. 2016; 65(3):1-103

5. Potter JE, Coleman-Minahan K, White K, Powers DA, Dillaway C, Stevenson AJ, et al. Contraception after delivery among publicly insured women in Texas: use compared with preference. Obstet Gynecol. 2017;130(2):393-402. https://doi.org/10.1097/AOG.0000000000002136.

6. Steenland MW, Pace LE, Sinaiko AD, Cohen JL. Association between South Carolina Medicaid's change in payment for immediate postpartum longacting reversible contraception and birth intervals. JAMA. 2019;322(1):76-8. https://doi.org/10.1001/jama.2019.6854.

7. Rodriguez MI, Dissanayake M, Swartz JJ, Funkhouser S, Baldwin MK. Immediate postpartum, long-acting reversible contraceptive use among the emergency Medicaid population: continuation rates and satisfaction. Am J Obstet Gynecol. 2020;222(4S):S913-S4. https://doi.org/10.1016/j.ajog.201 9.11.1289.

8. Okoroh EM, Kane DJ, Gee RE, Kieltyka L, Frederiksen BN, Baca KM, et al. Policy change is not enough: engaging provider champions on immediate postpartum contraception. Am J Obstet Gynecol. 2018;218(6):590 e1-7.

9. Moniz MH, Chang T, Heisler M, Admon L, Gebremariam A, Dalton VK, et al. Inpatient postpartum long-acting reversible contraception and sterilization in the United States, 2008-2013. Obstet Gynecol. 2017;129(6):1078-85. https://doi.org/10.1097/AOG.0000000000001970.

10. Moniz MH, Soliman AB, Kolenic GE, Tilea A, Fendrick AM, Bell S, Dalton VK Cost sharing and utilization of postpartum intrauterine devices and contraceptive implants among commercially insured women. Womens Health Issues. 2019;29(6):465-70. https://doi.org/10.1016/j.whi.2019.07.006. Epub 2019 Sep 5.

11. Centers for Medicare \& Medicaid Services. Adult health care quality measures; 2020. Available from: https://www.medicaid.gov/medicaid/qua lity-of-care/performance-measurement/adult-and-child-health-care-qualitymeasures/adult-health-care-quality-measures/index.html

12. Moniz M, Chang T, Heisler M, Dalton VK. Immediate postpartum long-acting reversible contraception: the time is now. Contraception. 2017;95(4):335-8. https://doi.org/10.1016/j.contraception.2016.11.007.

13. Palm HC, Degnan JH, Biefeld SD, Reese AL, Espey E, Hofler LG. An initiative to implement immediate postpartum long-acting reversible contraception in rural New Mexico. Am J Obstet Gynecol. 2020;222(4S):S911 e1-S e7.
14. Brown JA, Greenfield LT, Rapkin RB. Special report: implementing immediate postpartum LARC in Florida. Am J Obstet Gynecol. 2020;222(4S):S906-S9. https://doi.org/10.1016/j.ajog.2019.11.1268.

15. Lacy MM, McMurtry Baird S, Scott TA, Barker B, Zite NB. Statewide quality improvement initiative to implement immediate postpartum long-acting reversible contraception. Am J Obstet Gynecol. 2020;222(4S):S910 e1-S e8.

16. Desisto CL, Estrich C, Kroelinger CD, Goodman DA, Pliska E, Mackie CN, et al. Using a multi-state learning community as an implementation strategy for immediate postpartum long-acting reversible contraception. Implement Sci. 2017;12(1):138. https://doi.org/10.1186/s13012-017-0674-9.

17. Hofler LG, Cordes S, Cwiak CA, Goedken P, Jamieson DJ, Kottke M. Implementing immediate postpartum long-acting reversible contraception programs. Obstet Gynecol. 2017;129(1):3-9. https://doi.org/10.1097/AOG. 0000000000001798.

18. Harper KD, Loper AC, Louison LM, Morse JE. Stage-based implementation of immediate postpartum long-acting reversible contraception using a reproductive justice framework. Am J Obstet Gynecol. 2020;222(4S):S893905. https://doi.org/10.1016/j.ajog.2019.11.1273.

19. Ovretveit J. Understanding the conditions for improvement: research to discover which context influences affect improvement success. BMJ Qual Saf. 2011;20(Suppl 1):i18-23. https://doi.org/10.1136/bmjas.2010.045955.

20. Powell BJ, Waltz TJ, Chinman MJ, Damschroder LJ, Smith JL, Matthieu MM, et al. A refined compilation of implementation strategies: results from the expert recommendations for implementing change (ERIC) project. Implement Sci. 2015;10(1):21. https://doi.org/10.1186/s13012-015-0209-1.

21. Goodrick D. Comparative case studies: methodological briefs - impact evaluation no. 9; 2014. Available from: https://www.unicef-irc.org/publications/754-compara tive-case-studies-methodological-briefs-impact-evaluation-no-9.html

22. Baxter P, Jack S. Qualitative case study methodology: study design and implementation for novice researchers. Qual Rep. 2008;13(4):544-59 Retrieved from https://nsuworks.nova.edu/tqr/vol13/iss4/2.

23. Tong A, Sainsbury P, Craig J. Consolidated criteria for reporting qualitative research (COREQ): a 32-item checklist for interviews and focus groups. Int J Qual Health Care. 2007;19(6):349-57. https://doi.org/10.1093/intahc/mzm042.

24. Patton M. Qualitative research and evaluation methods. 3rd ed. Thousand Oaks: Sage Publications; 2002.

25. Kuper $A$, Lingard $L$, Levinson W. Critically appraising qualitative research. BMJ. 2008;337:a1035. https://doi.org/10.1136/bmj.a1035.

26. Malterud K. Qualitative research: standards, challenges, and guidelines. Lancet. 2001;358(9280):483-8. https://doi.org/10.1016/S0140-6736(01)05627-6.

27. Tellis WM. Application of a case study methodology. Qual Rep. 1997;3(3):1-19.

28. Damschroder LJ, Aron DC, Keith RE, Kirsh SR, Alexander JA, Lowery JC. Fostering implementation of health services research findings into practice: a consolidated framework for advancing implementation science. Implement Sci. 2009;4(1):50. https://doi.org/10.1186/1748-5908-4-50.

29. Proctor E, Silmere H, Raghavan R, Hovmand P, Aarons G, Bunger A, et al. Outcomes for implementation research: conceptual distinctions, measurement challenges, and research agenda. Admin Pol Ment Health. 2011;38(2):65-76. https://doi.org/10.1007/s10488-010-0319-7.

30. Damschroder LJ, Lowery JC. Evaluation of a large-scale weight management program using the consolidated framework for implementation research (CFIR). Implement Sci. 2013;8(1):51. https://doi.org/10.1186/1748-5908-8-51.

31. Bonawitz $\mathrm{K}$, Wetmore $\mathrm{M}$, Heisler M, Dalton VK, Damschroder $\mathrm{U}$, Forman J, et al. Champions in context: which attributes matter for change efforts in healthcare? Implement Sci. 2020;15(1):62. https://doi.org/10.1186/s13012-02 0-01024-9.

32. Ling VB, Levi EE, Harrington AR, Zite NB, Rivas SD, Dalton VK, Smith R, Moniz $\mathrm{MH}$. The cost of improving care: a multisite economic analysis of hospital resource use for implementing recommended postpartum contraception programmes. BMJ Qual Saf. 2020:bmjqs-2020-011111. https://doi.org/10.113 6/bmjqs-2020-011111. Epub ahead of print.

33. Damschroder LJ, Banaszak-Holl J, Kowalski CP, Forman J, Saint S, Krein SL. The role of the champion in infection prevention: results from a multisite qualitative study. Qual Saf Health Care. 2009;18(6):434-40. https://doi.org/1 0.1136/qshc.2009.034199

34. Soo S, Berta W, Baker GR. Role of champions in the implementation of patient safety practice change. Healthc Q. 2009;12 Spec No Patient:123-8.

35. Marsteller JA, Woodward P, Underwood WS, Hsiao CJ, Barr MS. Design of a quality and performance improvement project for small primary care practices: reflections on the Center for Practice Innovation. Qual Prim Care. 2011;19(1):49-57. 
36. Kuehl H, Mabry L, Elliot DL, Kuehl KS, Favorite KC. Factors in adoption of a fire department wellness program: champ-and-chief model. J Occup Environ Med. 2013;55(4):424-9. https://doi.org/10.1097/JOM.0b013e3182 $7 \mathrm{dba3f}$.

37. Shaw EK, Howard J, West DR, Crabtree BF, Nease DE Jr, Tutt B, et al. The role of the champion in primary care change efforts: from the state networks of Colorado ambulatory practices and partners (SNOCAP). J Am Board Fam Med. 2012;25(5):676-85. https://doi.org/10.3122/jabfm.2012.05.110281.

38. Clack L, Zingg W, Saint S, Casillas A, Touveneau S, da Liberdade JF, et al. Implementing infection prevention practices across European hospitals: an in-depth qualitative assessment. BMJ Qual Saf. 2018;27(10):771-80. https:// doi.org/10.1136/bmjgs-2017-007675.

39. Moniz MH, Chang T, Davis MM, Forman J, Landgraf J, Dalton VK. Medicaid administrator experiences with the implementation of immediate postpartum long-acting reversible contraception. Womens Health Issues. 2016;26(3):313-20. https://doi.org/10.1016/j.whi.2016.01.005.

40. Moniz MH, Dalton VK, Davis MM, Forman J, lott B, Landgraf J, et al. Characterization of Medicaid policy for immediate postpartum contraception. Contraception. 2015;92(6):523-31. https://doi.org/10.1016/j. contraception.2015.09.014.

41. Rodriguez Ml, Evans M, Espey E. Advocating for immediate postpartum LARC: increasing access, improving outcomes, and decreasing cost. Contraception. 2014;90(5):468-71. https://doi.org/10.1016/j.contraception.2 014.07.001.

42. Bombard Y, Baker GR, Orlando E, Fancott C, Bhatia P, Casalino S, et al. Engaging patients to improve quality of care: a systematic review. Implement Sci. 2018;13(1):98. https://doi.org/10.1186/s13012-018-0784-z.

43. Harris LH, Wolfe T. Stratified reproduction, family planning care and the double edge of history. Curr Opin Obstet Gynecol. 2014;26(6):539-44. https://doi.org/10.1097/GCO.0000000000000121.

44. Moniz MH, Spector-Bagdady K, Heisler M, Harris LH. Inpatient postpartum long-acting reversible contraception: care that promotes reproductive justice. Obstet Gynecol. 2017;130(4):783-7. https://doi.org/10.1097/AOG. 0000000000002262.

45. Holt K, Reed R, Crear-Perry J, Scott C, Wulf S, Dehlendorf C. Beyond sameday long-acting reversible contraceptive access: a person-centered framework for advancing high-quality, equitable contraceptive care. Am J Obstet Gynecol. 2020;222(4S):S878 e1-S e6.

46. Butler M, Epstein RA, Totten A, Whitlock EP, Ansari MT, Damschroder LJ, et al. AHRQ series on complex intervention systematic reviews-paper 3: adapting frameworks to develop protocols. J Clin Epidemiol. 2017;90:19-27. https://doi.org/10.1016/j.jclinepi.2017.06.013.

47. Dopp AR, Parisi KE, Munson SA, Lyon AR. A glossary of user-centered design strategies for implementation experts. Transl Behav Med. 2019;9(6):1057-64. https://doi.org/10.1093/tbm/iby119.

48. Green T, Bonner A, Teleni L, Bradford N, Purtell L, Douglas C, et al. Use and reporting of experience-based codesign studies in the healthcare setting: a systematic review. BMJ Qual Saf. 2020;29(1):64-76. https://doi.org/10.1136/ bmjqs-2019-009570.

49. Altman M, Huang TTK, Breland JY. Design thinking in health care. Prev Chronic Dis. 2018;15:E117.

50. Fernandez ME, Ten Hoor GA, van Lieshout S, Rodriguez SA, Beidas RS, Parcel $\mathrm{G}$, et al. Implementation mapping: using intervention mapping to develop implementation strategies. Front Public Health. 2019;7:158. https://doi.org/1 0.3389/fpubh.2019.00158.

51. Damschroder LJ. Clarity out of chaos: use of theory in implementation research. Psychiatry Res. 2020;283:112461. https://doi.org/10.1016/j. psychres.2019.06.036.

52. Waltz TJ, Powell BJ, Fernandez ME, Abadie B, Damschroder LJ. Choosing implementation strategies to address contextual barriers: diversity in recommendations and future directions. Implement Sci. 2019;14(1):42. https://doi.org/10.1186/s13012-019-0892-4

53. Rogal SS, Chinman M, Gellad WF, Mor MK, Zhang H, McCarthy SA, et al. Tracking implementation strategies in the randomized rollout of a veterans affairs national opioid risk management initiative. Implement Sci. 2020;15(1): 48. https://doi.org/10.1186/s13012-020-01005-y.

54. Yakovchenko V, Miech EJ, Chinman MJ, Chartier M, Gonzalez R, Kirchner JE, et al. Strategy configurations directly linked to higher hepatitis c virus treatment starts: an applied use of configurational comparative methods. Med Care. 2020;58(5):e31-e8. https://doi.org/10.1097/MLR.0000000000001319.
55. Krause J, Van Lieshout J, Klomp R, Huntink E, Aakhus E, Flottorp S, et al. dentifying determinants of care for tailoring implementation in chronic diseases: an evaluation of different methods. Implement Sci. 2014;9(1):102. https://doi.org/10.1186/s13012-014-0102-3.

56. Proctor EK, Powell BJ, McMillen JC. Implementation strategies: recommendations for specifying and reporting. Implement Sci. 2013;8(1): 139. https://doi.org/10.1186/1748-5908-8-139.

\section{Publisher's Note}

Springer Nature remains neutral with regard to jurisdictional claims in published maps and institutional affiliations.

\section{Ready to submit your research? Choose BMC and benefit from:}

- fast, convenient online submission

- thorough peer review by experienced researchers in your field

- rapid publication on acceptance

- support for research data, including large and complex data types

- gold Open Access which fosters wider collaboration and increased citations

- maximum visibility for your research: over $100 \mathrm{M}$ website views per year

At BMC, research is always in progress.

Learn more biomedcentral.com/submissions 